\title{
$\kappa$ Opioid Receptor-Dynorphin Signaling in the Central Amygdala Regulates Conditioned Threat Discrimination and Anxiety
}

\author{
Madison A. Baird, ${ }^{1}$ TingTing Y. Hsu, ${ }^{1}$ Rachel Wang, ${ }^{1}$ Barbara Juarez, ${ }^{2}$ and Larry S. Zweifel ${ }^{1,2}$
}

https://doi.org/10.1523/ENEURO.0370-20.2020

${ }^{1}$ Department of Pharmacology, University of Washington, Seattle, WA 98115 and ${ }^{2}$ Department of Psychiatry and Behavioral Sciences, University of Washington, Seattle, WA 98115

\begin{abstract}
Neuropeptides within the central nucleus of the amygdala $(\mathrm{CeA})$ potently modulate neuronal excitability and have been shown to regulate conditioned threat discrimination and anxiety. Here, we investigated the role of $\kappa$ opioid receptor $(\mathrm{KOR})$ and its endogenous ligand dynorphin in the $\mathrm{CeA}$ for regulation of conditioned threat discrimination and anxiety-like behavior in mice. We demonstrate that reduced KOR expression through genetic inactivation of the KOR encoding gene, Oprk1, in the CeA results in increased anxiety-like behavior and impaired conditioned threat discrimination. In contrast, reduction of dynorphin through genetic inactivation of the dynorphin encoding gene, Pdyn, in the CeA has no effect on anxiety or conditioned threat discrimination. However, inactivation of Pdyn from multiple sources, intrinsic and extrinsic to the CeA phenocopies Oprk1 inactivation. These findings suggest that dynorphin inputs to the CeA signal through KOR to promote threat discrimination and dampen anxiety.
\end{abstract}

Key words: anxiety; central amygdala; dynorphin; fear; $\kappa$; opioid

\section{Significance Statement}

The regulation of fear and anxiety-related behavior are critically dependent on the central nucleus of the amygdala $(\mathrm{CeA})$ region of the brain. Here, we demonstrate that signaling through the $\kappa$ opioid receptor $(\mathrm{KOR})$ in the $\mathrm{CeA}$ regulates conditioned threat discrimination and anxiety related behavior mice. These findings have broad implications for the neural mechanisms that regulate conditioned threat and anxiety-related behavior.

\section{Introduction}

Anxiety-related disorders, including phobias, obsessive compulsive disorders, generalized anxiety, and posttraumatic stress disorder (PTSD) display heterogeneous symptoms. Many of these disorders are based in aberrant information processing of fear-inducing stimuli, resulting in inappropriate responses to perceived threats as well as the sustained state of apprehension known as anxiety (Davis et al., 2010). Learning to discriminate between predictive and non-predictive threat stimuli is adaptive; however, non-discriminative, or

Received August 24, 2020; accepted November 24, 2020; First published December 15, 2020

The authors declare no competing financial interests. generalized threat responding is often maladaptive and is a hallmark of many fear-related disorders (Dunsmoor and Paz, 2015). In experimental systems, such as rodents, conditioned threat discrimination is assessed by pairing an unconditioned stimulus (US) with a conditioned stimulus (CS+). Comparing conditioned responses evoked by the CS + with responses evoked by an unpaired stimulus (CS-) provides a metric of threat discrimination (Zweifel, 2019).

The amygdala is a key brain region for regulating affective behavior and emotional learning (LeDoux, 2000). The

Author contributions: M.A.B. and L.S.Z. designed research; M.A.B., T.Y.H., R.W., and B.J. performed research; L.S.Z. contributed unpublished reagents/ analytic tools; M.A.B., T.Y.H., R.W., and L.S.Z. analyzed data; M.A.B. and L.S.Z. wrote the paper. 
extended amygdala which includes the central nucleus of the amygdala $(\mathrm{CeA})$, bed nucleus of the stria terminalis (BNST), and nucleus accumbens (NAc) shell is also critically involved regulating affective behavioral responses (Fox et al., 2015). The CeA is a heterogeneous and interconnected structure that has emerged as an important central regulator for the acquisition, consolidation, and expression of conditioned threat (Ciocchi et al., 2010; Haubensak et al., 2010; Li et al., 2013) and anxiety-related behavior (Tye et al., 2011; Botta et al., 2015). Anatomically, the $\mathrm{CeA}$ is divided into three subregions, the capsular $(\mathrm{CeC})$, lateral $(\mathrm{CeL})$, and medial $(\mathrm{CeM})$ subdivisions; which have divergent inputs, outputs, and roles in fear learning (Duvarci and Pare, 2014). Critical plasticity and local reciprocal inhibition occur during fear learning in the $\mathrm{CeL}$, which inhibits CeM output neurons mediating freezing and defensive behaviors (Ciocchi et al., 2010; Haubensak et al., 2010; Li et al., 2013). Additionally, the $\mathrm{CeC}$ receives dense inputs from the lateral parabrachial nucleus (LPN) signaling the US information to neurons expressing PKC $\delta$ and Calcrl (Dong et al., 2010; Han et al., 2015; Kim et al., 2017). Thus, the $\mathrm{CeA}$ acts as a hub relaying information related to threat discrimination by receiving cue-related signals from extra-amygdalar regions such as sensory cortices and the thalamus (Bienkowski and Rinaman, 2013; Duvarci and Pare, 2014), as well as from the lateral and basolateral amygdala (Tovote et al., 2015), and direct nociceptive information from the spinal parabrachial tract (Han et al., 2015).

Neuropeptides, including corticotropin releasing factor (CRF), dynorphin, enkephalin, tachykin 2, and neurotensin are highly enriched in the CeA (Kim et al., 2017; McCullough et al., 2018), where they have been shown to modulate multiple aspects of conditioned threat and anxiety-related behaviors (Regev et al., 2012; Andero et al., 2014; Fadok et al., 2017; Sanford et al., 2017; Ahrens et al., 2018; Dedic et al., 2018b; Jo et al., 2020). CRF and dynorphin are broadly linked to stress, fear, and anxiety (Land et al., 2008; Bruchas et al., 2009; Chavkin, 2013; Fadok et al., 2017; Sanford et al., 2017; Ahrens et al., 2018; Dedic et al., 2018a; Jo et al., 2020). While CRF is a direct mediator of the stress response, dynorphin is proposed to mediate the dysphoric effects of stress (Land et al., 2008). Broad activation of the dynorphin receptor, $\kappa$ opioid receptor (KOR), increases depression-like and anxiety-like behavior, and proaddictive behaviors (Shippenberg

This work was supported by National Institutes of Health Grants P50MH10642 and P30DA048736 (to L.S.Z.).

Acknowledgements: We thank Dr. Richard Palmiter for the Pdyn ${ }^{\mathrm{Cre} /+}$ and $P d y n^{l o x / l o x}$ mice and Dr. Charles Chavkin for the Oprk1 $1^{l o x / l o x}$ mice. We also thank Jordan Elum for setting up a CellProfiler analysis in the laboratory, Dr. Michael Bruchas for the Retro-AAV2-FLEX-EFGP and Dr. James Allen for assistance with AAV production, and members of the Zweifel laboratory for their thoughtful comments during the preparation of this manuscript.

Correspondence should be addressed to Larry S. Zweifel at larryz@uw.edu.

https://doi.org/10.1523/ENEURO.0370-20.2020

Copyright @ 2021 Baird et al.

This is an open-access article distributed under the terms of the Creative Commons Attribution 4.0 International license, which permits unrestricted use, distribution and reproduction in any medium provided that the original work is properly attributed. et al., 2001; Land et al., 2008; Bruchas et al., 2009; Chavkin, 2013). Dynorphin also mediates a variety of adaptive responses to stress, such as analgesia and aversion which increases the motivation to escape from a threat (Knoll and Carlezon, 2010).

Within the CeA, dynorphin is known to increase after acute stress (Chung et al., 2014; Xie et al., 2017; Nation et al., 2018) or local application of CRF (Lam and Gianoulakis, 2011). Dynorphin expression is also increased in CeA somatostatin (SOM)-expressing neurons in a mouse model of anxiety (Ahrens et al., 2018). Suppression of Pdyn expression in CRF neurons of the CeA reduces conditioned threat responses (Pomrenze et al., 2019) and pharmacological inhibition of KOR in the CeA disrupts fear-potentiated startle (Knoll et al., 2011); however, the role of KOR-dynorphin signaling in the $\mathrm{CeA}$ for threat discrimination remains to be addressed.

To examine the role of $\mathrm{CeA} \mathrm{KOR}$ and dynorphin in discriminative fear learning and anxiety-like behavior, we reduced Oprk1 and Pdyn expression in the CeA by injecting floxed Oprk1 and floxed Pdyn mice with and adeno-associated virus (AAV) containing an expression cassette for Cre-EGFP (AAV1-Cre-EGFP). Somewhat surprisingly, we found that local CeA KOR, but not dynorphin, is necessary for maintaining normal baseline anxiety-like behavior in an elevated-plus maze (EPM) and for promoting conditioned threat discrimination. In contrast to reducing local dynorphin within the $\mathrm{CeA}$, we found that reducing Pdyn expression from local and distal sources to the CeA using a retrograde viral delivery of Cre resulted in increased anxiety-like behavior and conditioned threat generalization. These findings suggest that normal anxiety and discriminative fear learning through KOR signaling in the CeA is likely dependent on distal sources of dynorphin.

\section{Materials and Methods}

\section{Mice}

Male and female Pdyn ${ }^{\mathrm{Cre} /+}$, Oprk ${ }^{\mathrm{Cre} /+}, \mathrm{Pdyn}^{\text {lox/lox }}$, Oprk ${ }^{\text {lox/lox }}$ mice on a C57BL/6 background were group-housed on a $12 / 12 \mathrm{~h}$ light/dark cycle with free access to food and water. Behavioral experiments were conducted during the light cycle (lights on at 7 A.M.). All procedures were approved by the University of Washington Institutional Care and Use Committee. Males and females were distributed evenly between groups.

\section{Virus production and surgery}

AAV1-FLEX-Synaptophysin-GFP, AAV1-Cre-GFP, AAV1FLEX-mCherry, AAV1-FLEX-EGFP, CAV2-Cre, and CAV2FLEX-ZsGreen were produced in house (titer $\sim 3 \times 1012$ particles/ $\mu$ l) as described previously (Gore et al., 2013). AAV2retro-FLEX-EYFP was produced by the Washington University Hope Center and was the gift of Michael Bruchas. Viral vectors were stored at $-80^{\circ} \mathrm{C}$ before surgery, and kept on ice on surgery day. Viral vectors were stereotaxically injected $(0.5 \mu \mathrm{l})$ at a rate of $0.25 \mu \mathrm{l} / \mathrm{min}$ bilaterally into the CeA of isofluorane-anesthetized mice (8-16 weeks old) using the following coordinates: -1.165 $\mathrm{mm}$ posterior, $\pm 2.91 \mathrm{~mm}$ lateral, and either -4.6 or -4.7 
ventral to bregma [according to the Paxinos' atlas (Paxinos and Franklin, 2001), average injection site was observed at $-1.4 \mathrm{~mm}$ posterior of bregma]. Controls for local knockout $(\mathrm{KO})$ were lox/lox injected with AAV1-FLEX-mCherry, wild-type animals injected with AAV1-Cre-GFP, and wild types injected with AAV1-FLEX-mCherry. Controls for retrograde CAV2-Cre mediated $\mathrm{KO}$ were wild-type animals injected with CAV2-FLEX-ZsGreen. All mice recovered from surgery for two to three weeks and experiments were run with 10- to 19-week-old mice. All animals used for behavior underwent stringent histology checks to confirm that the virus displayed a bilateral $\mathrm{CeA}$ hit without targeting surrounding regions such as the basolateral amygdala or the caudate putamen. Extra-CeA targeting or low levels of viral expression in the CeA usually resulted in $30-50 \%$ of mutants' data being removed from experiments.

\section{Anxiety: elevated-plus maze (EPM)}

EPM experiments were performed on a Med Associates EPM for mice (product \#ENV-560A) which has two "closed arms" with black walls, two "open arms" with 1-cm ledges, and white flooring; 10-min sessions begin as the mouse is placed in a closed arm of the arena, with its nose at the edge of the center area boundary. Sessions were recorded from above and mouse center point movement tracked by Ethovision (Noldus) tracking software. Total distance traveled, time spent in open and closed arms, latency to enter the open arm, and frequency of open arm entries were analyzed. Frequency of open arm entries was highly variable and deemed unreliable, as the center point of animals standing at the edge of open arm often togged between the open arm and center area, creating an artificially high number of open arm entries. No differences were found in distance traveled (data not shown) or latency to enter open arm (Extended Data Figs. 1-1, 2-1, 4-1), but anxiety phenotypes could be observed through changes in open and closed arm time; 1-(open arm time/closed arm time) was calculated, with a score of 1 showing maximal anxiety-like behavior that can be detected by this paradigm.

\section{Fear conditioning}

Fear conditioning sessions were performed during the light cycle in a standard operant chamber (Med Associates Inc.) equipped with a house light, tone generator, and shock grid. Our discriminative low threat intensity fear conditioning protocol is $3 \mathrm{~d}$ long and includes a baseline probe then shock training trial on day 1 , an intermediate probe and second shock training trial on day 2 , and a final probe on day 3.

During each training session, animals are exposed to 10 pairings of a CS + auditory tone with a 0.3-mA US footshock, and 10 CS- tone presentations which are never paired with shock. Auditory CS cues included a $10-\mathrm{kHz}$ pulsatile tone and a $20-\mathrm{kHz}$ continuous tone, each $10 \mathrm{~s}$ in duration. The CS+ tone co-terminated with a 0.5-s 0.3-mA footshock which began $9.5 \mathrm{~s}$ after the tone presentation began. Assignment of which tone would be the shock- paired CS + or non-shock paired CS- was counterbalanced across groups. CS + and CS- tone presentations alternated with a 60-s intertrial interval. The training context was all metal, with the shock grid floor, and the box was cleaned with $70 \%$ ethanol between trials.

Baseline and probe trials were tested in a separate context, in an all-white Med-Associates box insert with a smooth floor which was cleaned with a $1 \%$ acetic acid between animals. The animals were exposed to alternating presentations of $3 \mathrm{CS}+$ and 3 CS- auditory tones (10-s tones as described above with a 60-s intertrial interval, but with no shock presentations). These trials were used to establish basal freezing to the tones on day 1 before shock training and to measure expression of learned fear of the tone(s).

All sessions were video recorded, and nose, center, and tail points were tracked on each mouse using Ethovision (Noldus) tracking software. Velocities were calculated using an in-house MATLAB (Mathworks) script, which calculates the animal's velocity given the movement of all three points. Freezing was defined as velocity $<1 \mathrm{~cm} / \mathrm{s}$ that lasted $\geq 0.5 \mathrm{~s}$. "\% freezing" was calculated as the \% of time during the 10-s CS tone that the animal was frozen. Probe trial \% freezing was presented as an average response to the $3 \mathrm{CS}+$ tones and the $3 \mathrm{CS}-$ tones for each experimental group during the day 1 baseline and the day 3 final probe. Training/acquisition freezing was presented as the 20 total CS + or CS- trials, binned into an average of two trials (ex: average of trials 1 and 2, 3, and 4, etc.). To measure shock reactivity, the raw center point velocity from Ethovision was graphed from $1 \mathrm{~s}$ before to $3 \mathrm{~s}$ after shock, for the first 10 shock trials.

\section{Histology and immunostaining}

Mice were anesthetized with $50 \mathrm{mg} / \mathrm{kg}$ of BeuthanasiaD and transcardially perfused with PBS, followed by $4 \%$ paraformaldehyde until the tissue was firm. Whole-brain tissue was dissected out and fixed overnight in $4 \%$ paraformaldehyde, and then cryoprotected by soaking in a $30 \%$ sucrose in PBS for $48 \mathrm{~h}$. The brains were frozen in $\mathrm{OCT}$ in a $-20^{\circ} \mathrm{C}$ cryostat and then cryosection to produce $30-\mu \mathrm{m}$-thick sections. Brain sections of interest were collected in PBS with $0.1 \% \mathrm{NaAz}$ before immunostaining.

For whole-brain retrograde labeling experiments, every section was collected, and a section was stained for every $90 \mu \mathrm{m}$ (approximately corresponding to one page in the Paxinos atlas), or every $180 \mu \mathrm{m}$ for projection analysis. For CeA-specific immunostaining, sections were selected based on the Paxinos and Franklin reference atlas, selecting sections which cover the length of the $\mathrm{CeA}(\mathrm{y}=-1.2$ to -1.18 .).

Selected sections to stain were washed in tris-buffered saline (TBS) for $10 \mathrm{~min}$ then blocked in TBS $+0.3 \%$ Triton X-100 (TBST) $+3 \%$ normal donkey serum (NDS) for $30 \mathrm{~min}$. Then sections were incubated overnight in primary antibody diluted in TBST+NDS. Anti-GFP (polyclonal, 1:2000; Invitrogen A11122; polyclonal, 1:1000, Abcam ab13970) was used to stain for GFP and eYFPtagged viruses and anti-dsRed (polyclonal, 1:2000; 
Clontech, 632496) was used for mCherry-tagged viruses.

$\mathrm{CeA} \mathrm{Pdyn}{ }^{+}$synaptophysin distal projections were quantified by collecting the whole brain then staining sections (for GFP, as described above) every $180 \mu \mathrm{m}$. Because of GFP expression in the cell bodies in the CeA, the density of projections in the $\mathrm{CeA}$ could not be quantified. Six extra-amygdalar projections were identified and quantified by drawing regions of interest (ROIs) around the target region. We measured the density of GFPtagged projections by measuring the sum of the values of the pixels in the ROI (RawlntDen) and dividing that by the area of the ROI.

For the $\mathrm{Pdyn}^{+}$retrograde projection labeling experiment, cells were counted throughout the whole brain. The location of labeled cells was determined using the Paxinos and Franklin mouse brain atlas. Normalized cell count per region was calculated as [region count/(mouse total labeled cells/average total cells)].

\section{RNAscope in situ hybridization}

The RNAscope assay (Wang et al., 2012) performed on Bl6 wild-type, Oprk lox/lox, and Pdyn lox/lox adult mice. Viral vectors were injected (as described above) two to three weeks before brains were quickly excised, flash frozen in 2-methylbutane, and stored at $-80^{\circ} \mathrm{C} ; 20-\mu \mathrm{m}$ brain slices were prepared spanning the $\mathrm{CeA}$ from -1.2 to 1.8 $\mathrm{mm}$ posterior of bregma (according to the Paxinos atlas). Sections were prepared for hybridization per manufacturer's (Advanced Cell Diagnostics, Inc) instructions using probes for Cre (Mm-Cre-C2, ACD bio \#312281-C2), Pdyn (Mm-Pdyn-C3, ACD bio \#318771), and Oprk (Mm-OprkC3, ACD bio \#316111-C2). Slides were coverslipped and imaged using Nikon Upright Widefield fluorescent microscope at $10 \times$ magnification. Analysis performed using ImageJ.

Paxinos and Franklin's mouse brain atlas was used to determine $\mathrm{CeA}$ and subregion locations. Imaging exposure was chosen based on a reference area which did not receive Cre-GFP (the basolateral amygdala for Oprk, and the caudate putamen for Pdyn). Expression in the CeA and $\mathrm{KO}$ was measured as number of cells in the CeA-expressing the gene of interest. Gene expression was quantified from $y=-1.23$ to -1.79 (atlas pages $41-46$ ), and $\mathrm{KO}$ was quantified over five sections from $\mathrm{y}=-1.31$ to -1.79 for Oprk and six sections from $y=-1.23$ to -1.79 for Pdyn, based on location of gene expression. A cell was determined to express the gene of interest if there were more than three transcript puncta associated with the same nucleus (visualized using DAPI Fluoromount-G). Cell counting and $\mathrm{KO}$ quantification was performed for each unilateral injection. After noting differences in transcript expression level per cell between CeA subregions, we compared the density of transcript being expressed per subregion using ImageJ. Pixel density was calculated by measuring the sum of the values of the pixels in the ROI (RawlntDen) divided by the area of the ROI.

Additional analysis of $\mathrm{KO}$ was performed on $10 \times \mathrm{im}$ ages using CellProfiler software, to assess gene expression using integrated pixel intensity per cell. Nuclei (primary objects) were identified using DAPI (threshold strategy: global, thresholding method: two-class Otsu, method for distinguishing clumped objects: intensity, dividing lines between clumped objects method = propagate) and cells (secondary objects) were identified as the nucleus expanded by a distance of three pixels.

\section{Results}

\section{KOR signaling in the CeA regulates anxiety-like behavior and discriminative threat conditioning}

Previous studies of mRNA expression indicate that a fraction of cells in the CeM and CeL express Oprk1 (Zhu and Pan, 2004; Chieng et al., 2006; Bloodgood et al., 2020). KOR activation has also been shown to reduce synaptic transmission throughout the $\mathrm{CeA}$ and hyperpolarize a portion of CeM cells (Zhu and Pan, 2004; Chieng et al., 2006; Kang-Park et al., 2013). To better resolve the distribution of Oprk1 expression in the CeA we used RNAscope fluorescent in situ hybridization to probe for Oprk1 mRNA. Oprk1 was found to be expressed in all three subregions, with the most Oprk $1^{+}$cells in the CeM (Fig. $1 A-C$ ). Although the CeM possessed the largest number of Oprk $1^{+}$cells, the highest levels of expression were observed in the CeL (Extended Data Fig. 1-1A, $B$ ).

To determine whether KOR signaling in the $\mathrm{CeA}$ regulates anxiety-like behavior and conditioned threat discrimination, we inactivated Oprk1 by injecting Oprk1 $1^{\text {lox/lox }}$ mice with AAV1-Cre-EGFP bilaterally into the CeA (Fig. $1 D$ ). Because of the high levels of Oprk1 expression in the adjacent BLA and the known role of BLA KOR in regulating fear and anxiety (Knoll et al., 2011), we used a dilute virus and excluded all mice with viral spread into adjacent structures. This resulted in a significant reduction in Oprk1 mRNA levels across the entire rostral to caudal CeA (Fig. 1E,F), although the effect was modest given the stringent criterion for inclusion. Partial KO of Oprk1 in the $\mathrm{CeA}($ Oprk1 KO) resulted in a significant increase in anxiety-like behavior as measured by time spent in the closed arms of an EPM and a shift in the fraction of time spent in the closed versus open arms [graphed as 1-(open arm time/closed arm time) so that an increase in anxiety-like behavior is reflected by an increase in this fraction; Fig. $1 G-l]$.

Twenty-four hours following testing in the EPM, mice were assessed in a discriminatory threat conditioning paradigm (Fig. 1J). Before conditioning, baseline freezing was measured in response to three presentations of two distinct tones that would be used for pairing with the US during conditioning $(\mathrm{CS}+$ ) or that would be presented during conditioning but unpaired with the US(CS-). During conditioning, mice were trained for to two consecutive days in a different context than the probe test with 10 pairings of the CS+ tone that co-terminated with a 0.3$\mathrm{mA}$ footshock $(0.5 \mathrm{~s})$, and $10 \mathrm{CS}-$ tone presentations. Twenty-four hours following the last training session, mice were probed for retention by measuring freezing in response to three presentations of the CS+ and CStones. During acquisition training, both CeA Oprk1 KO and control mice responded equivalently to the US 

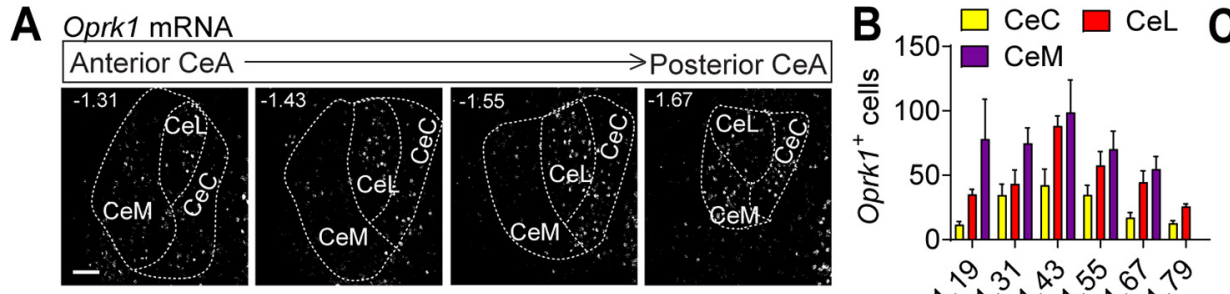

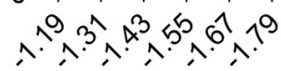

From Bregma $(\mathrm{mm})$
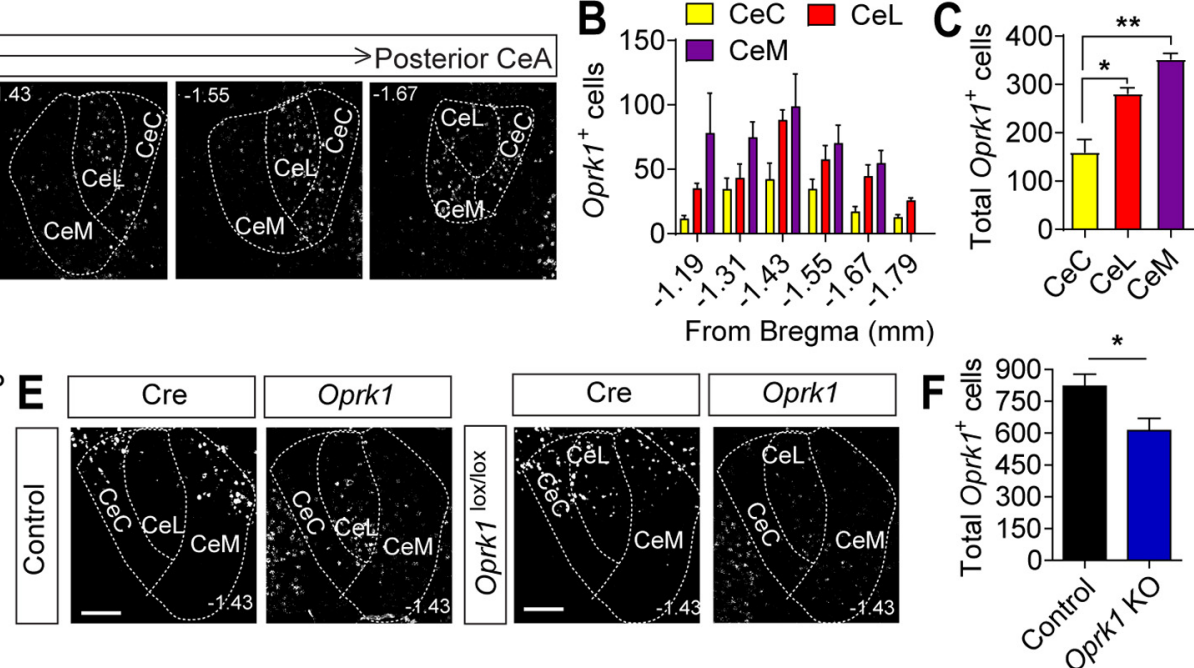

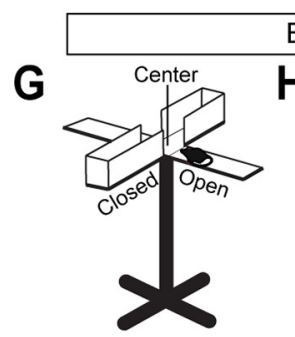

Elevated-plus maze
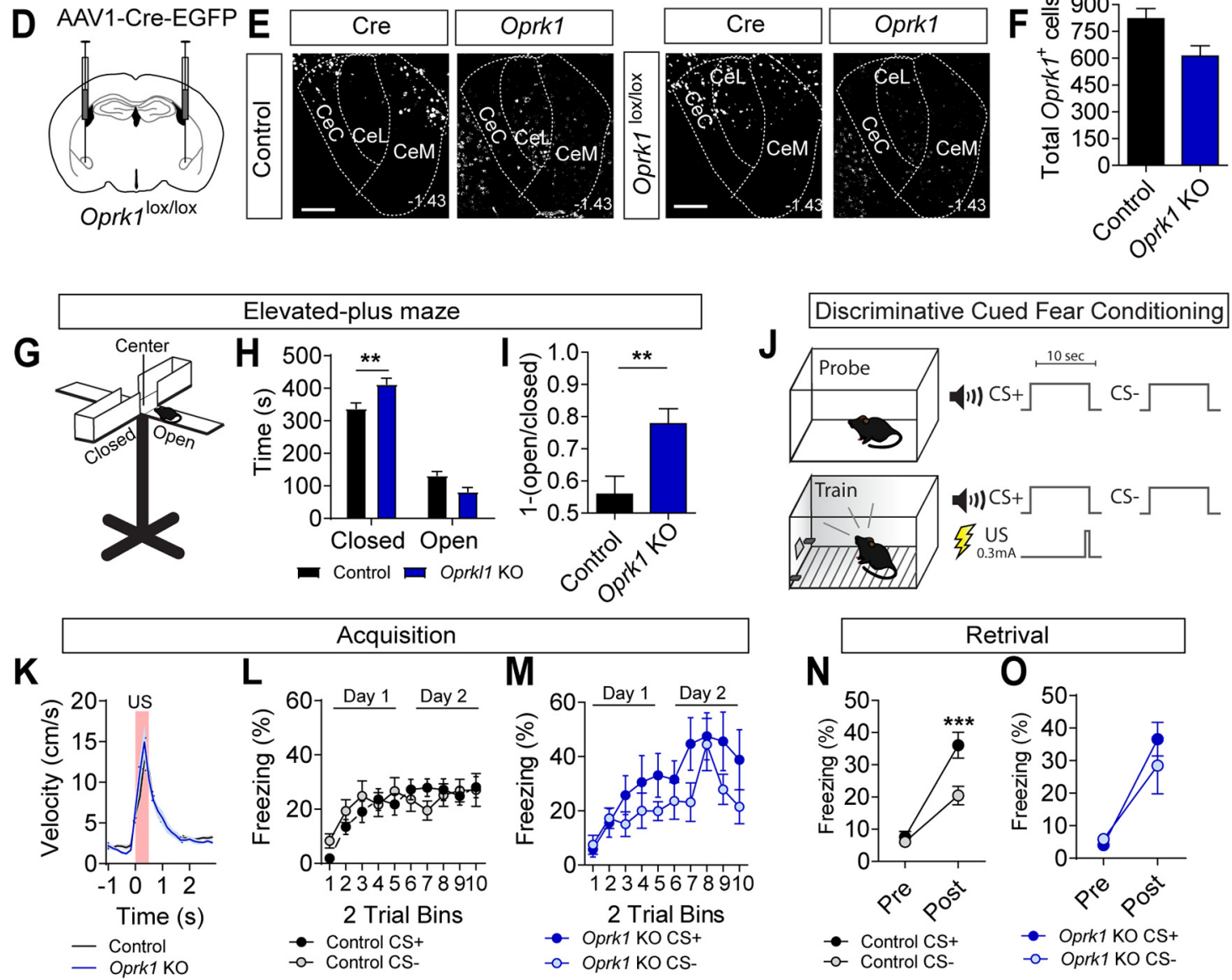
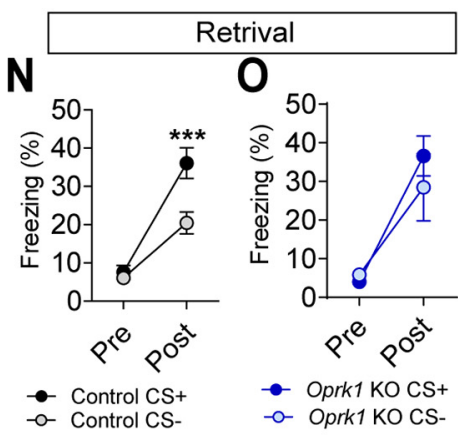

Figure 1. CeA Oprk1 expression and regulation of anxiety-like behavior and threat. $\boldsymbol{A}$, Representative images of Oprk1 mRNA expression along the rostral-caudal extent of the CeA. Scale bar: $100 \mu \mathrm{m}$. B. Distribution of cells along the rostral-caudal extent of the CeA-expressing Oprk1 ( $N=5$ mice). C , Distribution of cells expressing Oprk1 within the subdivisions of the CeA (one-way ANOVA, $F_{(2,12)}=30.23, p=0.01$, followed by Tukey's post hoc comparison test, $\left.{ }^{*} p<0.05,{ }^{* *} p<0.01\right)$. $D$, Schematic of injection for AAV1Cre-GFP into the CeA of Oprk $1^{\text {lox/lox }}$ mice. E, Oprk1 mRNA in the CeA of control (Oprk $\left.1^{+/+}\right)$and Oprk $1^{\text {lox/lox }}$ mice. Scale bar: $100 \mu$ m. $\boldsymbol{F}$, Quantification of Oprk1 mRNA-positive cells in the CeA following Cre expression in control $(N=5)$ and Oprk $1^{\text {lox/lox }}(N=4)$ mice $(S t u d e n t ' s$ $t$ test, $\left.{ }^{*} p<0.05\right)$. G, Cartoon of EPM consisting of open arms, closed arms, and a center transition zone. $\boldsymbol{H}$, Time spent in open and closed arms of the EPM in control $(N=24)$ and Oprk1 KO mice $(N=10)$, two-way ANOVA, $F_{(1,58)}=13.12, p=0.0006$, followed by Bonferroni's post hoc comparisons, $\left.{ }^{* *} p<0.01\right)$. I, [1-(open/closed arm time)] in control and Oprk1 KO mice (Student's $t$ test, $\left.{ }^{*} p<0.05\right)$. $\boldsymbol{J}$, Cartoon of discriminatory threat conditioning paradigm. Mice are probed for freezing in response to a CS + and CS- tone in context A (probe) before conditioning in context B (train). Following training, mice are again tested in context $A$ for conditioned threat responses to the CS+ and CS- tones. $K$, Average US responses in control $(N=24)$ and Oprk1 KO mice $(N=10)$ during training. $\boldsymbol{L}$, $\boldsymbol{M}$, Average CS+ and CS- freezing in control $(\boldsymbol{L})$ and Oprk1 KO mice $(\boldsymbol{M})$ during acquisition (control, $N=24$; Oprk1 KO, $N=10$ ). $\boldsymbol{N}, \boldsymbol{O}$, Average freezing to $\mathrm{CS}+$ and CS- during probe trials for retrieval in control $(\mathbf{N})$ and Oprk1 KO mice (O). Control but not Oprk1 KO mice showed significant cue discrimination during probe trials (two-way ANOVA, $F_{(1,40)}=7.79, p=0.008$, followed by Bonferroni's post hoc test, ${ }^{* * *} p<0.001$ ). All data are presented as mean \pm SEM. See also Extended Data Figure 1-1.

(Fig. 1K). Neither group displayed discrimination between the CS+ and CS- during conditioning (Fig. 1L,M); however, Oprk1 KO mice had higher freezing to the CS+ on average during the second day of conditioning compared with control mice (Extended Data Fig. 1-1C,D). During the probe for retrieval $24 \mathrm{~h}$ postconditioning, control mice showed robust discrimination between the CS+ and CS- (Fig. 1N) that was not observed in the CeA Oprk1 KO mice (Fig. 1O). 
Following fear conditioning, we assessed behavior in the EPM again in a subset of mice to investigate whether there were differential effects of threat conditioning stress on anxiety-like behavior. In this context, we still observed a slightly higher time spent in the closed arms; however, this effect was no longer significant because of increased anxiety-like behavior in control mice after fear conditioning (Extended Data Fig. 1-1E,F).

\section{Pdyn expression in the CeA does not regulate anxiety- like behavior or threat discrimination}

Given the high degree of interconnectivity of neurons within the CeA (Ciocchi et al., 2010), we hypothesized that inactivation of local dynorphin production in the CeA from the Pdyn gene would phenocopy inactivation of Oprk1 in the CeA. To confirm Pdyn expression in the CeA and delineate its anatomic distribution, we visualized Pdyn mRNA using in situ hybridization. Pdyn mRNA was localized throughout the rostral-to-caudal extent of the CeA with the highest numbers of $\mathrm{Pdyn}^{+}$cells in the CeL (Fig. $2 A-C)$, as was previously reported (Kim et al., 2017). To determine the projections of $\mathrm{CeA} \mathrm{Pdyn}{ }^{+}$cells, we performed viral projection mapping using Pdyn ${ }^{C r e /+}$ mice (Knoll et al., 2011). First, we confirmed the efficacy of viral labeling in the $\mathrm{CeA}$ by injecting $\mathrm{Pdyn} \mathrm{Cre}^{++}$mice with AAV1-FLEX-mCherry. Consistent with our in situ analysis, we observed robust viral labeling in the CeA of Pdyn Cre/+ mice (Extended Data Fig. 2-1A,B). Next, we injected AAV1-FLEX-Synaptophysin-EGFP into the CeA of $P d y n^{\mathrm{Cre} /+}$ mice to visualize neuronal projections. We observed dense synaptophysin-GFP labeling within the CeL and $\mathrm{CeM}$, as well as projections outside the CeA to the BNST, substantia nigra (SN), the midbrain reticular nucleus (Rt), and the LPN (Fig. 2D,E).

To determine whether inactivation of Pdyn from neurons within the $\mathrm{CeA}$ is sufficient to phenocopy the inactivation of Oprk1 in this region, injected AAV1-Cre-EGFP bilaterally into the CeA of Pdyn ${ }^{\text {lox/lox }}$ mice (Fig. $2 F$ ). Using a similar strict exclusion criterion as described for Oprk1 inactivation, we observed a significant reduction in Pdyn mRNA levels in the CeA (Fig. 2G,H) which was comparable to CeA Pdyn KO reported elsewhere (Bloodgood et al., 2020). In contrast to the observations made following a reduction in Oprk1 levels, a reduction in Pdyn did not alter behavior in the EPM (Fig. 2/,J). Likewise, we did not observe any significant effect of $P d y n$ reduction in the $\mathrm{CeA}$ on discriminatory threat conditioning during either acquisition (Fig. 2K-M; Extended Data Fig. 2-1C,D) or retrieval (Fig. 2M-O). In rats, knock-down of Pdyn expression with shRNA in Crh-expressing neurons of the CeA reduces freezing to a CS+ (Pomrenze et al., 2019). Although we observed a reduction in CS+-evoked freezing, this effect was not significant (Fig. 2P,Q). We also did not observe significant effects in the EPM in post-threat conditioned mice (Extended Data Fig. 2-1E,F).

\section{Inactivation of Pdyn from local and distal sources increases anxiety-like behavior and reduces threat discrimination}

One potential explanation for the lack of an observed effect of Pdyn reduction on discriminatory threat conditioning and anxiety-like behavior is that dynorphin is also released from inputs to the $\mathrm{CeA}$ that arrive from outside the structure. To investigate whether there are distal sources of dynorphin inputs to the CeA, we injected a retrograde transducing virus with a Cre-conditional expression cassette for EGFP (Retro-AAV2-FLEX-EGFP) unilaterally into the $\mathrm{CeA}$ of $P d y n^{\mathrm{Cre} /+}$ mice (Fig. $3 A$ ). We observed EGFP expression throughout the anterior-posterior axis of the CeA (Fig. $3 B$ ). The majority of the injections were restricted to the $\mathrm{CeA}$, although we did observe a small amount of virus in the striatum along the injection tract (Extended Data Fig. 3-1A). Retrogradely labeled cells were observed in multiple brain regions, but predominantly in cortical and hypothalamic areas. The largest number of labeled cells were in the isocortex, cingulate, insular cortex, entorhinal cortex, and hypothalamus (Fig. 3C,D; Extended Data Fig. 3-1B).

To determine whether inactivation of Pdyn expression from a diversity of inputs to the CeA is sufficient to phenocopy the inactivation of Oprk1 on anxiety-like behavior and conditioned threat discrimination, we injected $P d y n^{10 x / l o x}$ and control $\left(P d y n^{+/+}\right)$mice with the retrograde transducing virus CAV2 containing an expression cassette for Cre recombinase (CAV2-Cre). To confirm the locations of the injection sites, we co-injected mice with an AAV containing a Cre-dependent expression cassette for EGFP (AAV1-FLEX-EGFP; Fig. 4A). Unlike $P d y n^{\text {lox/lox mice }}$ injected with AAV1-Cre-EGFP to KO local Pdyn in the CeA, Pdyn ${ }^{\text {lox/lox }}$ mice injected with CAV2-Cre and AAV1FLEX-EGFP (CAV KO) largely phenocopied Oprk1 inactivation. CAV KO mice had a significant increase in anxietylike behavior, as measured by an increased time in the closed arms and a trending decrease in time spent in the open arms of the EPM, relative to controls (Fig. 4B,C).

During acquisition training in the discriminative threat conditioning paradigm, CAV KO and control mice showed similar US responses and freezing to CS + and CS- tones during conditioning (Fig. 4D-F). Unlike Oprk1 reduction in the CeA, we did not observe significant effects of CAV KO on freezing during the acquisition (Extended Data Fig. 4$1 A, B)$. During retrieval, both control and CAV KO mice had significant threat discrimination in the $24 \mathrm{~h}$ probe trial (Fig. 4G,H); however, the discrimination index (CS+ minus CS-) was significantly reduced in CAV KO mice relative to controls (Fig. 4/) consistent with an increase in threat generalization. Like other groups, threat conditioning enhanced anxiety-like behavior similarly in control and CAV KO mice (Extended Data Fig. 4-1C,D).

\section{Discussion}

It has been well established that dynorphin and KOR play a critical role in response to stress and that the net effect of global KOR activation is dysphoria and anxiety (Pfeiffer et al., 1986; Nabeshima et al., 1992; McLaughlin et al., 2003; Land et al., 2008). This has led to the assumption that dynorphin acts as prostress molecule in all circuits. Our results suggest a more complex function of KOR-dynorphin signaling in which KOR signaling in $\mathrm{CeA}$ neurons promotes threat discrimination and is anxiolytic. Consistent with this notion, acute KOR activation results 
A Pdyn mRNA
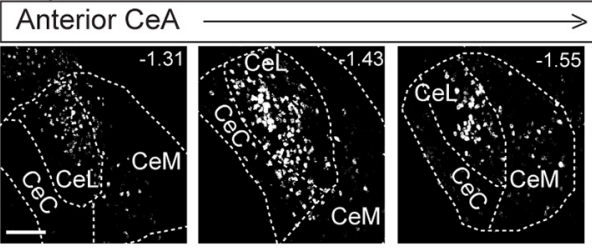

D

Pdyn-Cre:AAV-FLEX-Synaptophysin-EGFP
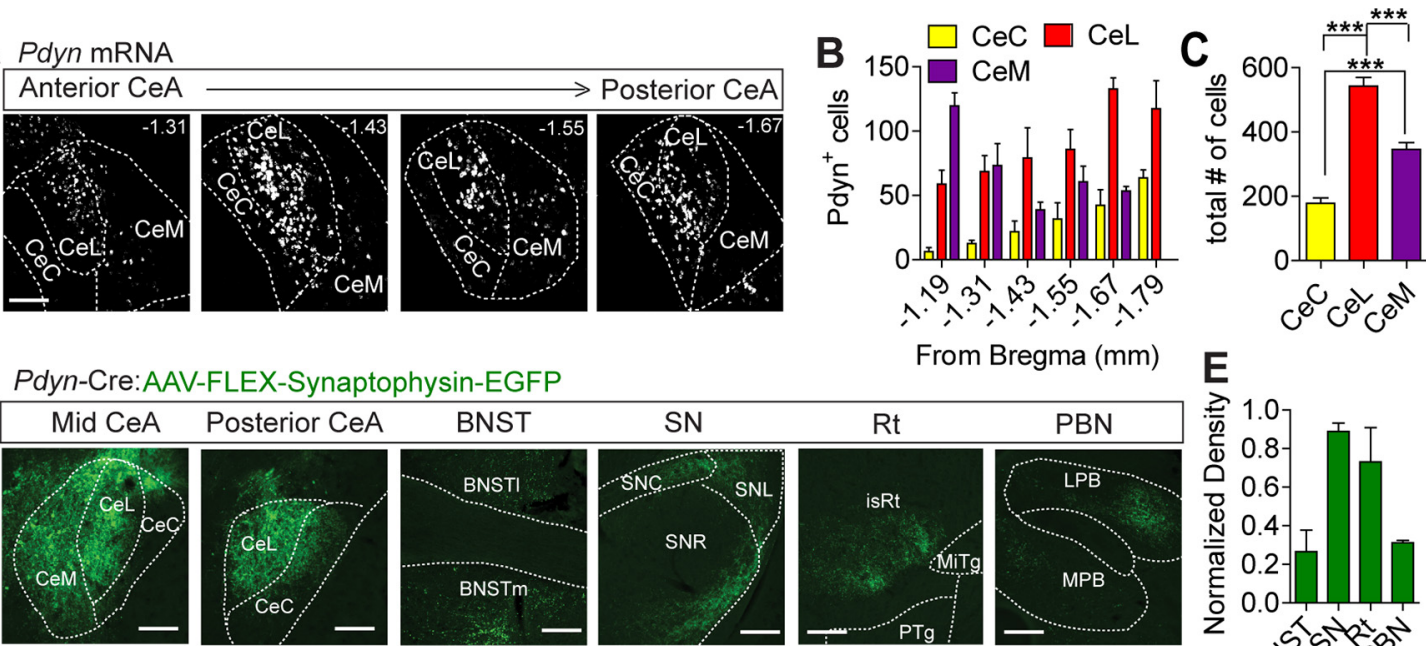

From Bregma (mm)

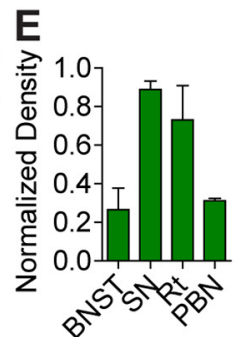

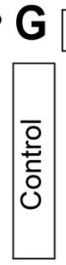
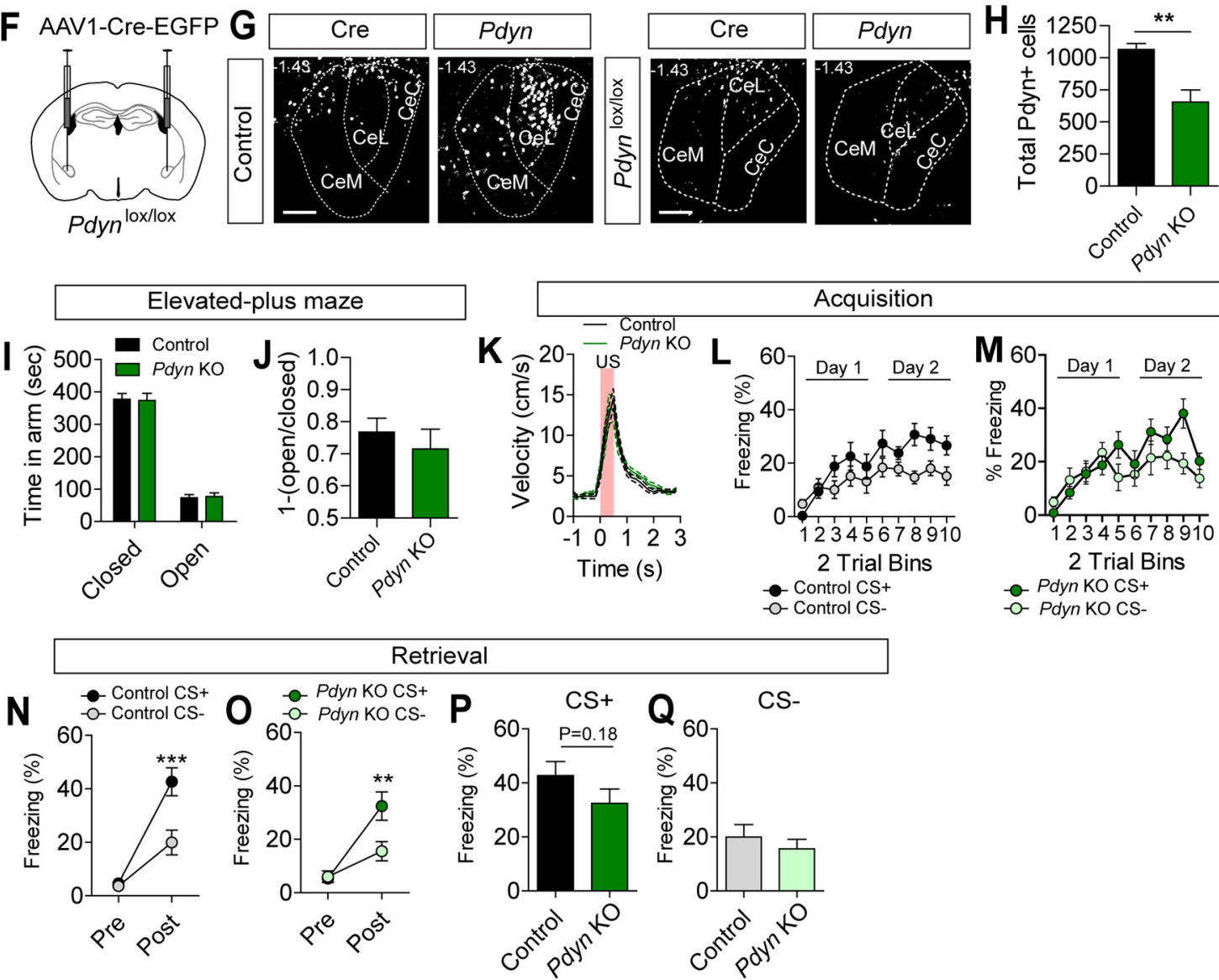

Figure 2. CeA Pdyn expression and regulation of anxiety-like behavior and threat. $\boldsymbol{A}$, Representative images of Pdyn mRNA expression along the rostral-caudal extent of the CeA. Scale bar: $100 \mu \mathrm{m}$. B. Distribution of cells along the rostral-caudal extent of the CeA-expressing Pdyn $(N=5)$. C , Distribution of cells expressing Pdyn within the subdivisions of the CeA (one-way ANOVA, $F_{(2,12)}=$ $67.34, p<0.0001$, followed by Tukey's post hoc comparison test, $\left.{ }^{* *} p<0.001\right)$. $\boldsymbol{D}$, Expression of Synaptophysin-EGFP in the CeA and projection targets of Pdyn ${ }^{\text {Cre/+ }}$ mice. Scale bar: $100 \mu \mathrm{m}$. E, Quantification of normalized projection densities for SynaptophysinEGFP levels in $P d y n^{\text {Cre/+ }}$ mice injected with AAV1-FLEX-Synaptophysin-EGFP into the CeA ( $N=3$ mice). BNST, bed nucleus of the stria terminalis; SN, substantia nigra; Rt, pontine reticular formation; PBN, parabrachial nucleus. $\boldsymbol{F}$, Schematic of injection for AAV1Cre-GFP into the CeA of Pdyn $n^{10 x / l o x}$ mice. G, Pdyn mRNA in the CeA of control $\left(P d y n^{+/+}\right)$and $P d y n^{10 x / l o x}$ mice. Scale bar: $100 \mu \mathrm{m} . \boldsymbol{H}$, Quantification of Pdyn mRNA-positive cells in the CeA following Cre expression in control $(N=5)$ and Pdyn $\mathrm{K}^{\text {lox/lox }}(N=3)$ mice (Student's $t$ test, $\left.{ }^{* *} p<0.01\right)$. $I$, Time spent in open and closed arms of the EPM in control $(N=9)$ and Pdyn KO $(N=9)$ mice. $J$, [1-(open/closed arm time)] in control and Pdyn KO mice. $K$, Average US responses in control $(N=14)$ and Pdyn KO mice $(N=14)$ during training. $\boldsymbol{L}, \boldsymbol{M}$, Average CS+ and CS- freezing in control $(\boldsymbol{L})$ and Pdyn KO mice $(\boldsymbol{M})$ during acquisition. $\boldsymbol{N}, \mathbf{O}$, Average freezing 
continued

to CS+ and CS- during probe trials for retrieval in control $(\boldsymbol{N}, N=17)$ and Pdyn KO mice $(\boldsymbol{O}, N=14)$. Both control and $P d y n \mathrm{KO}$ mice showed significant cue discrimination during probe trials (control: two-way ANOVA, $F_{(1,32)}=6.51, p=0.004$, followed by Bonferroni's post hoc test, ${ }^{\star \star \star} p<0.001$; Pdyn KO: two-way ANOVA, $F_{(1,26)}=7.05, p=0.008$, followed by Bonferroni's post hoc test, $\left.{ }^{\star \star \star} p<0.001\right)$. $\boldsymbol{P}, \boldsymbol{Q}$, No significant effects of $P d y n$ KO were observed on freezing to the CS + $(\boldsymbol{P}$, Student's $t$ test, $p=0.18)$ or CS- $(\boldsymbol{Q}$, Student's $t$ test, $p=0.47$ ). All data are presented as mean \pm SEM. See also Extended Data Figure 2-1.

in a variety of adaptive responses to threat, including analgesia which likely increases an organism's ability to cope or escape from noxious stimuli (Knoll and Carlezon, 2010; Chavkin, 2013). Additionally, dynorphin in the NAc suppresses attentional responding to non-predictive cues, further supporting a role of KOR-dynorphin signaling in discriminatory behavior (lordanova et al., 2006). Dysphoria and aversion, which is associated with a threat, motivates the organism to engage in behaviors to avoid the hazard in the future (Knoll and Carlezon, 2010).

Dynorphin is a signaling peptide and its effects are dependent on the localization of it inhibitory receptor, KOR. It has been previously demonstrated that dynorphin-KOR activation in adjacent subregions can result in opposing behavioral outcomes. It was demonstrated that stimulation of dynorphin populations in the ventral NAc shell was aversive, while stimulation of dynorphin cells in the adjacent dorsal NAc shell mediated place-preference and was positively reinforcing (Al-Hasani et al., 2015). Additionally, global Pdyn KO experiments resulted in enhancement of amygdala-mediated cued fear, but not hippocampusmediated contextual fear (Bilkei-Gorzo et al., 2012).

In the $\mathrm{CeA}$, previous work has shown that CeA KOR and CeA CRF receptor signaling have opposing effects on physiology in the CeA (Kang-Park et al., 2015). Given that CRF in the CeA is known to enhance threat responses (Fadok et al., 2017; Sanford et al., 2017; Jo et al., 2020), it is not surprising then that KOR suppresses threat responsiveness in this context. We observed Oprk1 expression to be widespread in the CeA with the highest number of Oprk $1^{+}$cells in the CeM with the highest density of Oprk1 mRNA levels in the CeL. It has also been shown that a proportion of CeL Oprk1-expressing neurons have overlapping expression with Pdyn (Bloodgood et al., 2020) and dynorphin co-localizes with SOM-expressing "fear on" neurons (Haubensak et al., 2010; Li et al., 2013; Kim et al., 2017; Ahrens et al., 2018). Thus, KOR-mediated inhibition of the CeL fear on neurons in addition to CeM output neurons would be predicted to lead to a decrease in overall CeA threat-related output signals.
A

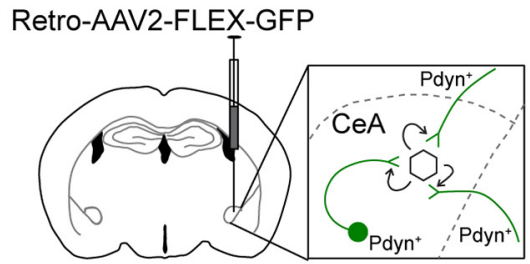

Pdyn-Cre

C.

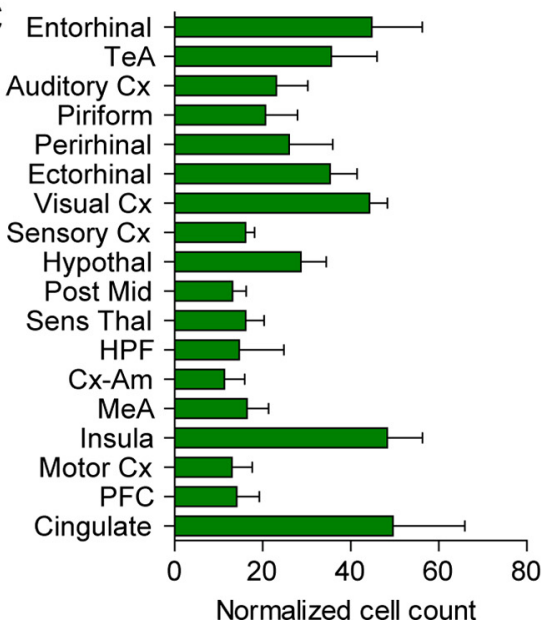

B

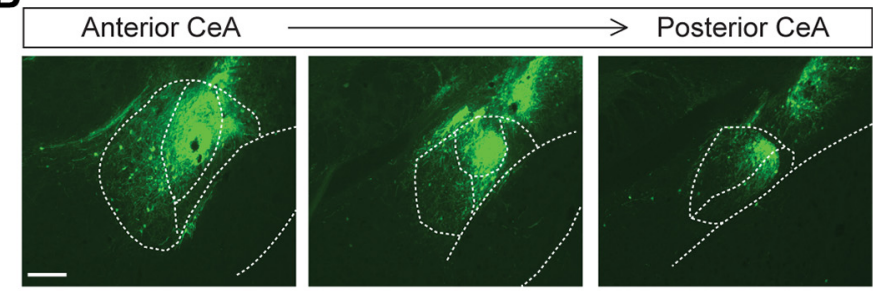

D
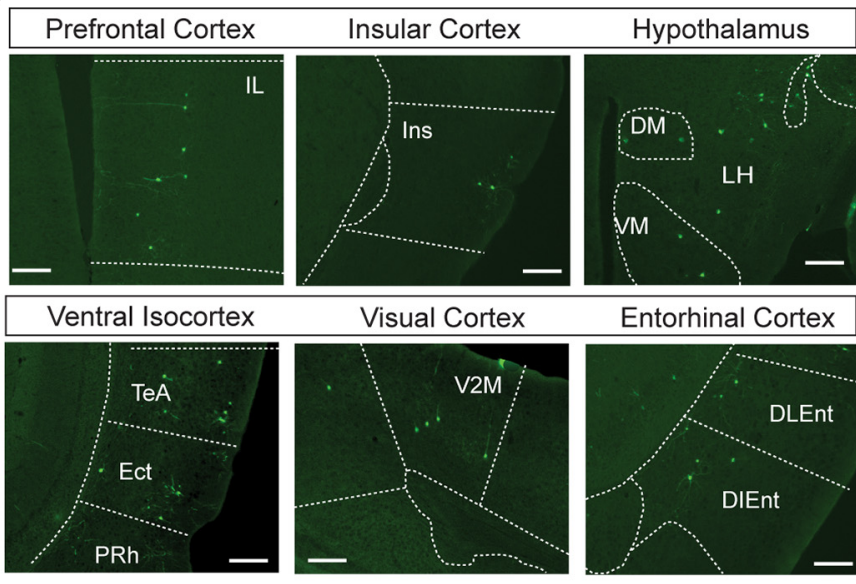

Figure 3. Pdyn inputs to the CeA. $\boldsymbol{A}$, Schematic of Retro-AAV2-FLEX-EGFP injection into the CeA of Pdyn Cre/+ mice. $\boldsymbol{B}$, Representative images of EGFP expression in the along the anterior-posterior axis of the CeA. Scale bar: $100 \mu \mathrm{m}$. $\boldsymbol{C}$, Distribution of relative cell numbers outside the CeA-expressing EGFP $\left(N=3\right.$ mice). $\boldsymbol{D}$, Representative images of $P d y n^{C r e}$-positive neurons expressing EGFP, largely in the cortex and hypothalamus. Scale bar: $100 \mu \mathrm{m}$. TeA, temporal association cortex; Cx, cortex; hypothal, hypothalamus; Mid, midbrain; sens thal, sensory thalamus; HPF, hippocampal formation; Cx-Am, cortex-amygdala transition zone; $\mathrm{MeA}$, medial amygdala; PFC, prefrontal cortex. Data are presented as the mean \pm SEM. See also Extended Data Figure 3-1. 
A Retro-CAV2-Cre + AAV1-FLEX-EGFP

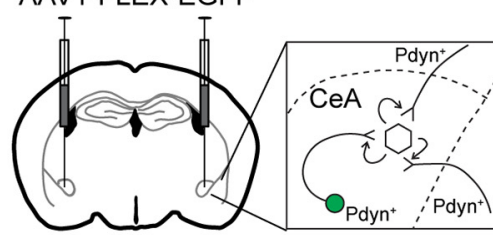

Pdyn $n^{10 x \mid 10 x}$
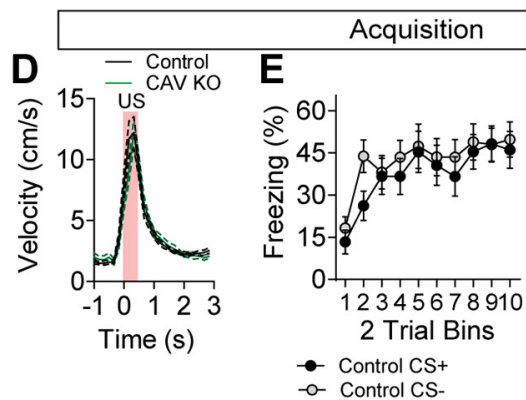
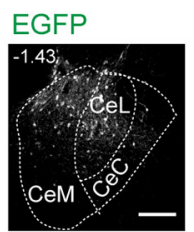

-
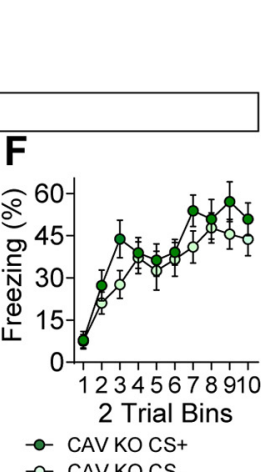

-o- CAVKO CS-
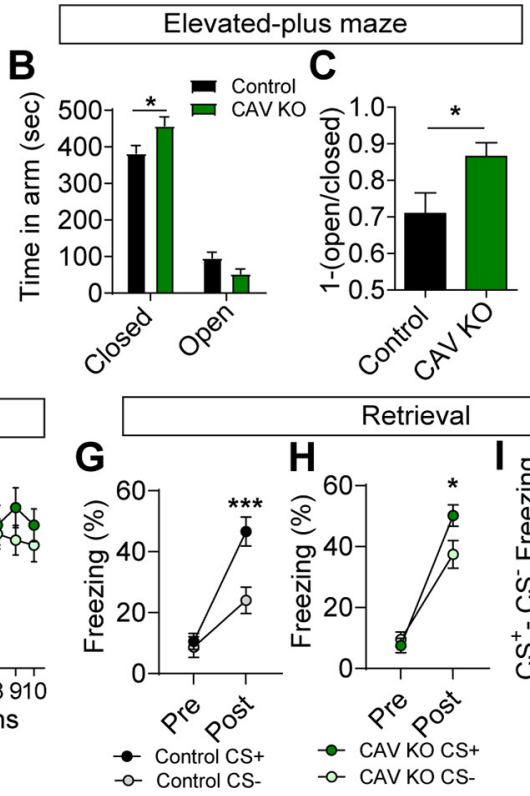

Figure 4. Inactivation of Pdyn in inputs to the CeA. $\boldsymbol{A}$, Schematic of injection for Retro-CAV2-Cre and AAV1-FLEX-EGFP into the $\mathrm{CeA}$ of $P d y n^{\text {lox/lox }}$ mice (left) and corresponding representative image of EGFP expression in the CeA. Scale bar: $100 \mu \mathrm{m}$. $\boldsymbol{B}$, Time spent in open and closed arms of the EPM in control $(N=15)$ and CAV KO mice $\left(N=11\right.$; two-way ANOVA, $F_{(3,72)}=3.95, p=0.012$, followed by Bonferroni's post hoc test, $\left.{ }^{*} p<0.05\right)$. $\boldsymbol{C}$, [1-(open/closed arm time)] in control and CAV KO mice (Student's $t$ test, $\left.{ }^{*} p<0.05\right)$. $\boldsymbol{D}$, Average US responses in control $(N=17)$ and CAV KO mice $(N=14)$ during training. $\boldsymbol{E}$, $\boldsymbol{F}$, Average CS + and CS- freezing in control $(\boldsymbol{E})$ and CAV KO mice $(\boldsymbol{F})$ during acquisition (control, $N=17$; CAV KO, $N=14$ ). $\boldsymbol{G}, \boldsymbol{H}$, Average freezing to CS+ and CSduring probe trials for retrieval in control $(\boldsymbol{G})$ and CAV KO mice $(\boldsymbol{H})$. Both control and Pdyn KO mice showed significant cue discrimination during probe trials (control: two-way ANOVA, $F_{(1,32)}=8.00, p=0.0002$, followed by Bonferroni's post hoc test, ${ }^{* * *} p<0.001$; CAV KO: two-way ANOVA, $F_{(1,26)}=2.87, p=0.046$, followed by Bonferroni's post hoc test, $\left.{ }^{*} p<0.05\right)$. $I$, Discrimination index $[(C S+)$ - (CS-)] is significantly reduced in CAV KO mice relative to controls (Student's $t$ test, ${ }^{*} p<0.05$ ). All data are presented as mean \pm SEM. See also Extended Data Figure 4-1.

The effects of reducing KOR in the CeA on basal anxiety-like behavior was not previously identified (Bloodgood et al., 2020). One possible explanation for this discrepancy is that the previous study performed their alcoholnaive, basal anxiety assays in mice that had been singly housed for one to three weeks, whereas our mice are group housed. Social isolation stress has been reported to modify neural circuits regulating anxiety and to increase anxiety-like behavior ( $\mathrm{Da}$ Silva et al., 1996; Matthews et al., 2016). Our assessment of anxiety-like behavior in mice following threat conditioning demonstrates that stress can mask basal differences observed in stress-naive mice. These authors also looked at sex-specific effects on alcohol consumption. In our data, there were no obvious differences in behavioral trends between males and females. For every experiment performed, male and female data were separated and assessed for trending differences, of which none were found, so male and female data were combined.

The role of dynorphin in the CeA for the regulation of alcohol consumption has been well described (Gilpin and Roberto, 2012; Anderson et al., 2019; Bloodgood et al., 2020). Several studies have also investigated the role of KOR-dynorphin in the CeA for the regulation of fear and anxiety. Using a fear-potentiated startle paradigm where rats receive KOR antagonist infusions between postfearconditioning startle sessions, pharmacological inhibition of $\mathrm{KOR}$ in the $\mathrm{CeA}$ reduced conditioned startle (Knoll et al., 2011). It is not entirely surprising that their pharmacological manipulation of conditioned startle and our genetic manipulation of cued conditioned freezing implicated divergent roles for $\mathrm{CeA} \mathrm{KOR}$. Behavior task differences aside, we inactivated Oprk1 only in CeA neurons, whereas antagonist infusion blocks KOR signaling at the level of the cells in the $\mathrm{CeA}$ as well as on terminals of neurons projecting into the $\mathrm{CeA}$.

In addition to KOR, dynorphin has also been studied in the $\mathrm{CeA}$ in the context of fear-related and anxiety-related behavior. Dynorphin is increased in SOM-expressing neurons in the CeA in a mouse model of anxiety that is proposed to increase KOR-dynorphin in the BNST to promote increased anxiety-like behaviors (Ahrens et al., 2018). We did not observe a change in anxiety-like behavior following conditioning in CeA Pdyn KO mice, consistent with previous assessment of CeA-Pdyn $\mathrm{KO}$ in the EPM (Bloodgood et al., 2020). It has also been shown that dynorphin $\mathrm{KO}$ in CeA CRF neurons in rats reduces freezing during probe trials (Pomrenze et al., 2019). We observed a modest reduction in freezing to the CS + that did not reach significance although the reductions in Pdyn levels are comparable. This difference could be because of the manipulation of slightly different dynorphin populations, non-selective here versus $\mathrm{Crh}$-selective in the rat. These differences could also be a reflection of the magnitude of the US, we use a moderate US that promotes discrimination in mice whereas the US used in the previous 
study in higher and results in a higher level of overall freezing. Thus, the effects of dynorphin produced in the CeA may only become evident at higher threat levels. Regardless of these minor differences, our findings reducing local Pdyn expression in the CeA does not phenocopy a reduction in Oprk1 levels in the CeA. This implies that a distal source of dynorphin, or a combination of local and distal dynorphin are required to signal through KOR within the CeA to suppress basal anxiety levels and promote conditioned threat discrimination. Our retrograde tracing suggests that the external sources of dynorphin could be cortical or hypothalamic and future investigations using combinatorial strategies should illuminate which of these inputs are critical, although it should be noted that the broad distribution of $\mathrm{Pdyn}^{+}$cells projecting to the CeA will make this a challenging task.

\section{References}

Ahrens S, Wu MV, Furlan A, Hwang G-R, Paik R, Li H, Penzo MA, Tollkuhn J, Li B (2018) A central extended amygdala circuit that modulates anxiety. J Neurosci 38:5567-5583.

Al-Hasani R, McCall JG, Shin G, Gomez AM, Schmitz GP, Bernardi JM, Pyo CO, Park SI, Marcinkiewcz CM, Crowley NA, Krashes MJ, Lowell BB, Kash TL, Rogers JA, Bruchas MR (2015) Distinct subpopulations of nucleus accumbens dynorphin neurons drive aversion and reward. Neuron 87:1063-1077.

Andero R, Dias BG, Ressler KJ (2014) A role for Tac2, NkB, and Nk3 receptor in normal and dysregulated fear memory consolidation. Neuron 83:444-454.

Anderson RI, Lopez MF, Griffin WC, Haun HL, Bloodgood DW, Pati D, Boyt KM, Kash TL, Becker HC (2019) Dynorphin-kappa opioid receptor activity in the central amygdala modulates binge-like alcohol drinking in mice. Neuropsychopharmacology 44:10841092.

Bienkowski MS, Rinaman L (2013) Common and distinct neural inputs to the medial central nucleus of the amygdala and anterior ventrolateral bed nucleus of stria terminalis in rats. Brain Struct Funct 218:187-208.

Bilkei-Gorzo A, Erk S, Schürmann B, Mauer D, Michel K, Boecker H, Scheef L, Walter H, Zimmer A (2012) Dynorphins regulate fear memory: from mice to men. J Neurosci 32:9335-9343.

Bloodgood DW, Hardaway JA, Stanhope CM, Pati D, Pina MM, Neira S, Desai S, Boyt KM, Palmiter RD, Kash TL (2020) Kappa opioid receptor and dynorphin signaling in the central amygdala regulates alcohol intake. Mol Psychiatry. Available at https://doi.org/10. 1038/s41380-020-0690-z.

Botta P, Demmou L, Kasugai Y, Markovic M, Xu C, Fadok JP, Lu T, Poe MM, Xu L, Cook JM, Rudolph U, Sah P, Ferraguti F, Lüthi A (2015) Regulating anxiety with extrasynaptic inhibition. Nat Neurosci 18:1493-1500.

Bruchas MR, Land BB, Lemos JC, Chavkin C (2009) CRF1-R activation of the dynorphin/kappa opioid system in the mouse basolateral amygdala mediates anxiety-like behavior. PLoS One 4:e8528.

Chavkin C (2013) Dynorphin-still an extraordinarily potent opioid peptide. Mol Pharmacol 83:729-736.

Chieng BC, Christie MJ, Osborne PB (2006) Characterization of neurons in the rat central nucleus of the amygdala: cellular physiology, morphology, and opioid sensitivity. J Comp Neurol 497:910-927.

Chung S, Kim HJ, Kim HJ, Choi SH, Cho JH, Cho YH, Kim D-H, Shin KH (2014) Desipramine and citalopram attenuate pretest swim-induced increases in prodynorphin immunoreactivity in the dorsal bed nucleus of the stria terminalis and the lateral division of the central nucleus of the amygdala in the forced swimming test. Neuropeptides 48:273-280.

Ciocchi S, Herry C, Grenier F, Wolff SBE, Letzkus JJ, Vlachos I, Ehrlich I, Sprengel R, Deisseroth K, Stadler MB, Müller C, Lüthi A
(2010) Encoding of conditioned fear in central amygdala inhibitory circuits. Nature 468:277-282.

Da Silva NL, Ferreira VM, Carobrez A. d P, Morato GS (1996) Individual housing from rearing modifies the performance of young rats on the elevated plus-maze apparatus. Physiol Behav 60:1391-1396.

Davis L, Barlow DH, Smith L (2010) Comorbidity and the treatment of principal anxiety disorders in a naturalistic sample. Behav Ther 41:296-305.

Dedic N, Chen A, Deussing JM (2018a) The CRF family of neuropeptides and their receptors - mediators of the central stress response. Curr Mol Pharmacol 11:4-31.

Dedic N, Kühne C, Jakovcevski M, Hartmann J, Genewsky AJ, Gomes KS, Anderzhanova E, Pöhlmann ML, Chang S, Kolarz A, Vogl AM, Dine J, Metzger MW, Schmid B, Almada RC, Ressler KJ, Wotjak CT, Grinevich V, Chen A, Schmidt MV, et al. (2018b) Chronic $\mathrm{CRH}$ depletion from GABAergic, long-range projection neurons in the extended amygdala reduces dopamine release and increases anxiety. Nat Neurosci 21:803-807.

Dong YL, Fukazawa Y, Wang W, Kamasawa N, Shigemoto R (2010) Differential postsynaptic compartments in the laterocapsular division of the central nucleus of amygdala for afferents from the parabrachial nucleus and the basolateral nucleus in the rat. J Comp Neurol 518:4771-4791.

Dunsmoor JE, Paz R (2015) Fear generalization and anxiety: behavioral and neural mechanisms. Biol Psychiatry 78:336-343.

Duvarci S, Pare D (2014) Amygdala microcircuits controlling learned fear. Neuron 82:966-980.

Fadok JP, Krabbe S, Markovic M, Courtin J, Xu C, Massi L, Botta P, Bylund K, Müller C, Kovacevic A, Tovote P, Lüthi A (2017) A competitive inhibitory circuit for selection of active and passive fear responses. Nature 542:96-100.

Fox AS, Oler JA, Tromp DPM, Fudge JL, Kalin NH (2015) Extending the amygdala in theories of threat processing. Trends Neurosci 38:319-329.

Gilpin NW, Roberto M (2012) Neuropeptide modulation of central amygdala neuroplasticity is a key mediator of alcohol dependence. Neurosci Biobehav Rev 36:873-888.

Gore BB, Soden ME, Zweifel LS (2013) Manipulating gene expression in projection-specific neuronal populations using combinatorial viral approaches. Curr Protoc Neurosci 65:4.35.1-20.

Han S, Soleiman MT, Soden ME, Zweifel LS, Palmiter RD (2015) Elucidating an affective pain circuit that creates a threat memory. Cell 162:363-374.

Haubensak W, Kunwar PS, Cai H, Ciocchi S, Wall NR, Ponnusamy $\mathrm{R}$, Biag J, Dong H-W, Deisseroth K, Callaway EM, Fanselow MS, Lüthi A, Anderson DJ (2010) Genetic dissection of an amygdala microcircuit that gates conditioned fear. Nature 468:270-276.

Iordanova MD, McNally GP, Westbrook RF (2006) Opioid receptors in the nucleus accumbens regulate attentional learning in the blocking paradigm. J Neurosci 26:4036-4045.

Jo YS, Namboodiri VMK, Stuber GD, Zweifel LS (2020) Persistent activation of central amygdala CRF neurons helps drive the immediate fear extinction deficit. Nat Commun 11:422.

Kang-Park M, Kieffer BL, Roberts AJ, Siggins GR, Moore SD (2013) $\kappa$-Opioid receptors in the central amygdala regulate ethanol actions at presynaptic GABAergic sites. J Pharmacol Exp Ther 346:130-137.

Kang-Park M, Kieffer BL, Roberts AJ, Siggins GR, Moore SD (2015) Interaction of CRF and kappa opioid systems on GABAergic neurotransmission in the mouse central amygdala. J Pharmacol Exp Ther 355:206-211.

Kim J, Zhang X, Muralidhar S, LeBlanc SA, Tonegawa S (2017) Basolateral to central amygdala neural circuits for appetitive behaviors. Neuron 93:1464-1479 e5.

Knoll AT, Carlezon WA Jr (2010) Dynorphin, stress, and depression. Brain Res 1314:56-73.

Knoll AT, Muschamp JW, Sillivan SE, Ferguson D, Dietz DM, Meloni EG, Carroll FI, Nestler EJ, Konradi C, Carlezon WA (2011) Kappa 
opioid receptor signaling in the basolateral amygdala regulates conditioned fear and anxiety in rats. Biol Psychiatry 70:425-433.

Lam MP, Gianoulakis C (2011) Effects of corticotropin-releasing hormone receptor antagonists on the ethanol-induced increase of dynorphin A1-8 release in the rat central amygdala. Alcohol 45:621630.

Land BB, Bruchas MR, Lemos JC, Xu M, Melief EJ, Chavkin C (2008) The dysphoric component of stress is encoded by activation of the dynorphin kappa-opioid system. J Neurosci 28:407-414.

LeDoux JE (2000) Emotion circuits in the brain. Annu Rev Neurosci 23:155-184.

Li H, Penzo MA, Taniguchi H, Kopec CD, Huang ZJ, Li B (2013) Experience-dependent modification of a central amygdala fear circuit. Nat Neurosci 16:332-339.

Matthews GA, Nieh EH, Vander Weele CM, Halbert SA, Pradhan RV, Yosafat AS, Glober GF, Izadmehr EM, Thomas RE, Lacy GD, Wildes CP, Ungless MA, Tye KM (2016) Dorsal raphe dopamine neurons represent the experience of social isolation. Cell 164:617631.

McCullough KM, Morrison FG, Hartmann J, Carlezon WA, Ressler KJ (2018) Quantified coexpression analysis of central amygdala subpopulations. eNeuro 5. ENEURO.0010-18.2018.

McLaughlin JP, Marton-Popovici M, Chavkin C (2003) $\kappa$ Opioid receptor antagonism and prodynorphin gene disruption block stress-induced behavioral responses. J Neurosci 23:5674-5683.

Nabeshima T, Katoh A, Wada M, Kameyama T (1992) Stress-induced changes in brain Met-enkephalin, Leu-enkephalin and dynorphin concentrations. Life Sci 51:211-217.

Nation KM, De Felice M, Hernandez PI, Dodick DW, Neugebauer V, Navratilova E, Porreca F (2018) Lateralized kappa opioid receptor signaling from the amygdala central nucleus promotes stress-induced functial pain. Pain 159:919-928.

Paxinos G, Franklin KBJ (2001) The mouse brain in stereotaxic coordinates. 2nd edn. Academic Press.

Pfeiffer A, Braun S, Mann K, Meyer HD, Brantl V (1986) Anterior pituitary hormone responses to a kappa-opioid agonist in man. J Clin Endocrinol Metab 62:181-185.
Pomrenze MB, Giovanetti SM, Maiya R, Gordon AG, Kreeger LJ, Messing RO (2019) Dissecting the roles of GABA and neuropeptides from rat central amygdala CRF neurons in anxiety and fear learning. Cell Rep 29:13-21.e4.

Regev L, Tsoory M, Gil S, Chen A (2012) Site-specific genetic manipulation of amygdala corticotropin-releasing factor reveals its imperative role in mediating behavioral response to challenge. Biol Psychiatry 71:317-326.

Sanford CA, Soden ME, Baird MA, Miller SM, Schulkin J, Palmiter RD, Clark M, Zweifel LS (2017) A central amygdala CRF circuit facilitates learning about weak threats. Neuron 93:164-178.

Shippenberg TS, Chefer VI, Zapata A, Heidbreder CA (2001) Modulation of the behavioral and neurochemical effects of psychostimulants by kappa-opioid receptor systems. Ann NY Acad Sci 937:50-73.

Tovote P, Fadok JP, Lüthi A (2015) Neuronal circuits for fear and anxiety. Nat Rev Neurosci 16:317-331.

Tye KM, Prakash R, Kim S-Y, Fenno LE, Grosenick L, Zarabi H, Thompson KR, Gradinaru V, Ramakrishnan C, Deisseroth K (2011) Amygdala circuitry mediating reversible and bidirectional control of anxiety. Nature 471:358-362.

Wang F, Flanagan J, Su N, Wang L-C, Bui S, Nielson A, Wu X, Vo HT, Ma X-J, Luo Y (2012) RNAscope: a novel in situ RNA analysis platform for formalin-fixed, paraffin-embedded tissues. J Mol Diagn 14:22-29.

Xie JY, De Felice M, Kopruszinski CM, Eyde N, LaVigne J, Remeniuk B, Hernandez P, Yue X, Goshima N, Ossipov M, King T, Streicher JM, Navratilova E, Dodick D, Rosen H, Roberts E, Porreca F (2017) Kappa opioid receptor antagonists: a possible new class of therapeutics for migraine prevention. Cephalalgia 37:780-794.

Zhu W, Pan ZZ (2004) Synaptic properties and postsynaptic opioid effects in rat central amygdala neurons. Neuroscience 127:871879.

Zweifel LS (2019) Dopamine, uncertainty, and fear generalization. Curr Opin Behav Sci 26:157-164. 